\title{
SUXAMETHONIUM APNOEA
}

\author{
A Cautionary Tale \\ Major D. I. MACNAIR, M.B., B.S., F.F.A.R.C.S., R.A.M.C. \\ British Military Hospital, Hannover
}

AN athletic Corporal, aged 31 years, was admitted to a hospital in FARELF for diathermy reduction of a hypertrophic nasal turbinate. When seen before anaesthesia, he gave a history of several previous anaesthetics, including one two years before for the same operation in the same hospital. All had been, so far as he was concerned, without incident.

Following induction with thiopentone, he was given suxamethonium to facilitate oral intubation. Thereafter he remained apnoeic, though in good general condition. The procedure was completed in fifteen minutes and the patient was transferred, still apnoeic, to a Manley ventilator on a minute volume of 2 litres of oxygen and 6 of nitrous oxide. Thirty-five minutes after induction respiratory activity commenced and fifteen minutes later was judged to be normal. The patient was extubated and taken to the recovery ward where he made a rapid and uneventful return to consciousness.

The $\mathrm{F}$ Med 14 relating to the previous admission recorded no mischance, but the clinical notes from Archives revealed that apnoea of two and a half hours' duration had followed a similar dose of suxamethonium. On clinical grounds it was assumed that the patient has a genetically determined pseudocholinesterase deficiency; this was later confirmed by enzyme studies.

Further questioning of the patient did not reveal any positive family history and he was adamant that he had been told nothing of the previous incident. He was given a simple outline of the condition, was reassured that it was not of itself dangerous, and was given an explanatory letter to produce in the event of any future anaesthetic.

Two years later he was admitted to hospital in B.A.O.R. for a further nasal diathermy. Fortunately for him, he has an unusual name, and the author-then by coincidence also in B.A.O.R.-recognised it. Fortunately, because the patient failed either to produce the letter or to mention the incident. When taxed with this, he admitted that he had forgotten about the episode, although he still had the letter at home. Intubation was performed uneventfully under inhalation anaesthesia.

\section{Comment}

It is unfortunate that the first mishap was not recorded on the F. Med 14 relating to the admission, although this was rectified on the second occasion. A box on the F Med 4 is designed for the recording of sensitivities and, although a purist could argue that a genetic deficiency is not a sensitivity, this would seem a logical place in which to annotate such conditions. Alternatively, an insert in the F Med 4 -perhaps coloured or edged in red for easy identification-could perform a like function. At all events, some method of permanent recording seems indicated as there are many who are, like this patient, " to dumb Forgetfulness a prey" (Thomas Gray-Elegy written in a Country Churchyard). 